\title{
Is it reasonable to use existing outside soil spray seeding technology to prepare artificial soil under slope aspect and landslide in alpine area?
}

\author{
Xue Jiang ${ }^{1}$, Hao $\mathrm{Ai}^{2}$, Ke Zhu ${ }^{1}$, Bocong Huang ${ }^{1}$, Xiaoyan $\mathrm{Ai}^{1}$, and Ying-wei Ai ${ }^{1}$ \\ ${ }^{1}$ Sichuan University \\ ${ }^{2}$ Sichuan Normal University
}

March 21, 2021

\begin{abstract}
Knowledge about artificial soil nutrient of cut-slopes associated with slope aspect and landslide attributes is vital for understanding cut-slopes environmental ecosystem and establishing sustainable artificial soil management practices. Our study focuses on cut-slopes recovered by slope protect technology in alpine region, where slope aspect (east-, south-, west-, and north-facing slope) and landslide (non- and landslide) are dominant environment factors. Integrated matter-element model and path analysis were adopted to investigate the effects of slope aspect and landslide on the selected soil properties: $\mathrm{pH}$, soil organic matter (SOM), alkali-hydrolysable nitrogen (AN), total phosphorus (TP), available phosphorus (AP), and available potassium (AK). Both slope aspect and landslide had no significant effect on artificial soil $\mathrm{pH}(\mathrm{p}>0.05)$. Statistically significant differences were found for artificial SOM, AN, TP, AP, and AK between the slope aspect and landslide (p < 0.05). SOM, nitrogen $(\mathrm{N})$, and potassium $(\mathrm{K})$ were limiting factors for artificial soil nutrients on all slope aspect under landslide. $\mathrm{N}$ was a limiting factor for artificial soil nutrients on all slope aspect under non-landslide. $\mathrm{K}$ was a limiting factor for artificial soil nutrients on all slope aspect under non-landslide, except for non-landslide-north-facing slope, while SOM was a limiting factor for artificial soil nutrients on non-landslide-north-facing slope. Landslide and slope aspect had a highly significant positive correlation with AN and AK, but negative correlation with AP. Therefore, it is necessary to formulate different artificial soil management measures for different slope aspect and landslide to achieve the most effective slope ecological restoration.
\end{abstract}

\section{Hosted file}

$\backslash$ begin $\{\mathrm{CJK}\}\{\mathrm{UTF} 8\}\{$ gbsn $\} \backslash$ end $\{\mathrm{CJK}\} \backslash$ selectlanguage\{english\}2.1.pdf available at https: //authorea.com/users/402964/articles/514661-is-it-reasonable-to-use-existing-outsidesoil-spray-seeding-technology-to-prepare-artificial-soil-under-slope-aspect-andlandslide-in-alpine-area

\section{Hosted file}

$\backslash$ begin $\{$ CJK\} $\{$ UTF8\}\{gbsn\}. \end \{CJK\} \selectlanguage\{english\}pdf available at https://authorea. } com/users/402964/articles/514661-is-it-reasonable-to-use-existing-outside-soil-sprayseeding-technology-to-prepare-artificial-soil-under-slope-aspect-and-landslide-inalpine-area

\section{Hosted file}

Table.pdf available at https://authorea.com/users/402964/articles/514661-is-it-reasonableto-use-existing-outside-soil-spray-seeding-technology-to-prepare-artificial-soil-underslope-aspect-and-landslide-in-alpine-area 


\section{Hosted file}

Figure.pdf available at https://authorea.com/users/402964/articles/514661-is-it-reasonableto-use-existing-outside-soil-spray-seeding-technology-to-prepare-artificial-soil-underslope-aspect-and-landslide-in-alpine-area 